\title{
Foreword on the Contribution of the University of Kent's Applied Optics Group to the Field of Fiber Optics Sensors
}

\author{
David A. Jackson
}

Applied Optics Group, School of Physical Sciences, University of Kent, Canterbury, CT2 7NH, UK

E-mail: d.a.jackson@kent.ac.uk

\section{Introduction}

In this special issue of Photonic Sensors the research activities of some of the (ex) members of the Applied Optics Group (AOG) at the University of Kent (UoK) will present brief details of their research in AOG and then describe in greater length details of their careers since leaving the University. The research group has made significant contributions to many areas of "Fiber Optic Sensors" (FOS) as indicated in the "star diagram" below. This review is in recognition of the important advances made at AOG in the field of FOS and I was asked by Professor Y. Rao to organize it.

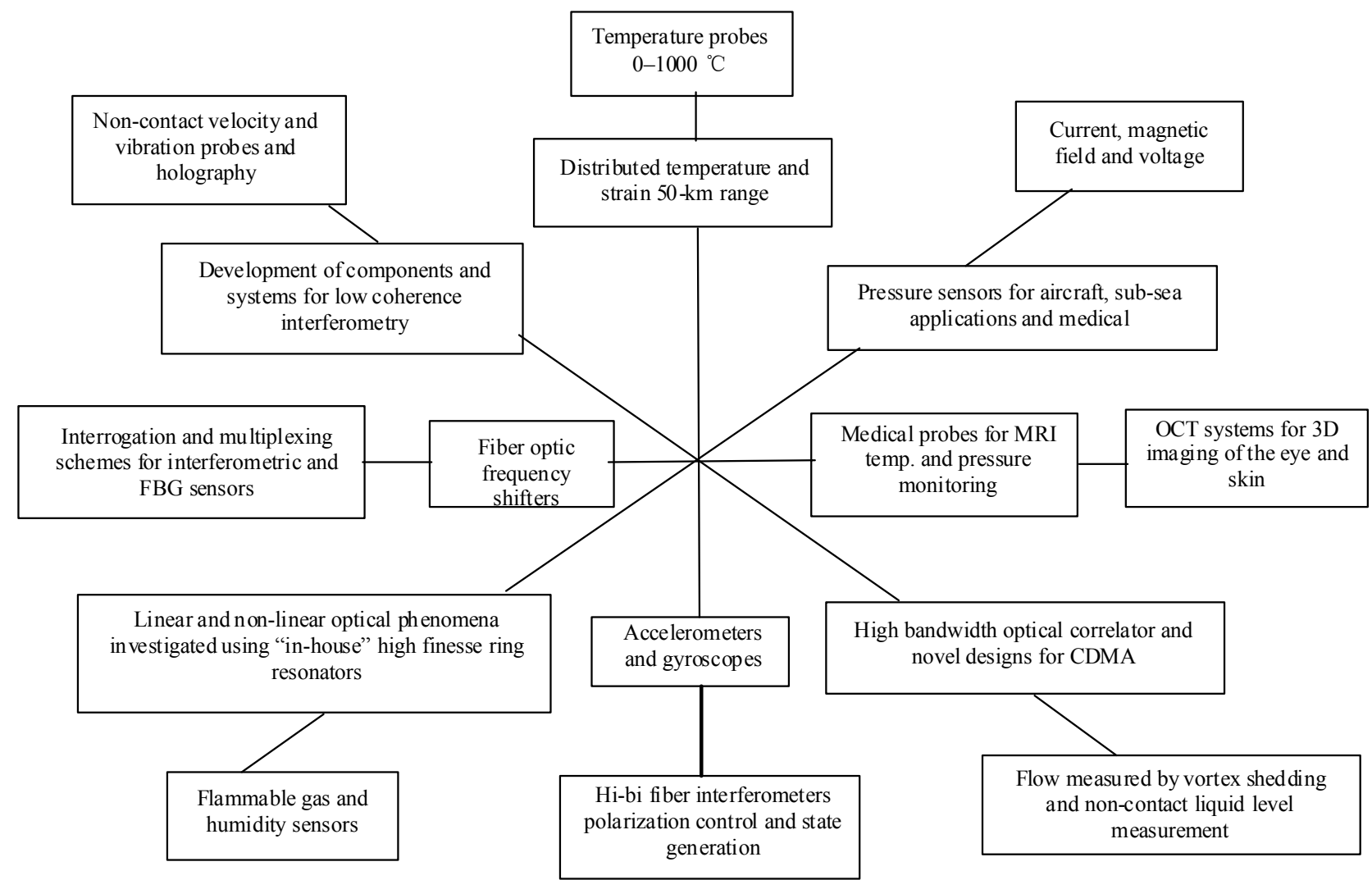

Star diagram shows some areas of research activity undertaken by group members.

(C) The Author(s) 2011.This article is published with open access at Springerlink.com 


\section{How it all started}

During the period 1976-1980 I spent time on leave of absence from UoK at the Naval Research Lab (NRL) in Washington. I was involved in two rather different projects, firstly to develop a very high contrast triple pass Fabry-Perot interferometer to study the cause of instabilities in chemicals used for rocket propellants. Secondly to develop a system to determine the minimum detectable phase shift (MDPS) that could be detected with an all single mode fiber optic interferometer, this project had a major impact on the rest of my research career. At the time I had not worked with single mode fiber optic waveguides or laser diodes. Initial experiments were performed with an available ultra-stable Michelson interferometer made of invar illuminated with a stable single mode He-Ne laser. The MDPS recorded was $10^{-6} \mathrm{rads} / \sqrt{ } \mathrm{Hz}$ at $10^{2} \mathrm{~Hz}$. The next step was to build an all fiber Mach Zehnder interferometer (MZI). This was at a time when directional couplers, fiber cleavers, fiber splicer's, fiber launchers to couple light from a laser to a single mode fiber and pigtailed lasers etc. were not commercially available. Despite these limitations an all fiber MZI was successfully realized using "in-house" components. Operating under normal laboratory conditions the outputs of the interferometer were constantly varying due to the interferometer's sensitivity to random temperature fluctuations, air currents and acoustic noise. In order to determine the MDPS the fiber interferometer placed in a specially designed chamber to isolate the MZI from acoustic and environmental noise [1]. The MDPS achieved was $10^{-5} \mathrm{rads} / \sqrt{\mathrm{Hz}}$ at $10^{2} \mathrm{~Hz}$. These experiments showed that it was feasible to use fiber optic interferometers as sensors to detect weak signals generated by any measurand which could couple into the fiber such as vibration or a temperature change. In order that the MZI could be used as a sensor it was necessary to stabilize its operating point which was achieved with a closed loop servo [2]. Although this approach worked well in the laboratory in general it would not have been practical for remote sensing especially as it is desirable to have electrically passive sensors. Another requirement for a practical interferometric sensor is that it has to be interrogated remotely; this was achieved using a single frequency laser diode with an unbalanced MZI. Here the absolute frequency of the laser diode is chirped by modulating the laser's drive current, if the chirp is periodic then heterodyne schemes can be used for signal recovery. Although the amplitude of the recovered signal increases with path imbalance the laser phase noise increases at the same rate imposing restrictions on the performance and design of fiber optic interferometric sensors.

Whilst I was at NRL I arranged for Tony Dandridge to undertake my teaching duties at UoK and to spend some time at NRL on the project, the outcome was that he was invited to stay and research on FOS. He is now head of the Optics Branch at NRL.

On my return to the UK I started a fiber optic sensing group with grants devoted to basic research giving great flexibility with the type of measurand that could be addressed. I am extremely fortunate to have had many highly talented people working in the group, several of whom have gone on to achieve great distinction in the field of FOS and have contributed to this issue.

\section{Brief details of the structure of the special Issues}

Due to the specified maximum number of pages in each issue it has been necessary to publish this review in two separate parts.

The authors contributing to Part 1 (Issue 2) are Professor Xiaoyi Bao, Professor Faramarz Farahi, Professor Adrian Podoleanu, Dr. Alan Kersey, Professor José Luís Santos, Dr. António Ribeiro, 
Dr. David Webb and for Part 2 the intending authors might include Dr. Kyriacos Kalli, Dr. Andy Lewin, Professor David Sampson, Professor Ralph Tatam, Professor Yunjiang Rao, Professor Tongyu Liu.

There are many very successful ex members of the group who are unable to make a contribution to the journal due to other commitments. Possibly the most well known is Prof. Julian Jones, a brilliant theoretician and experimentalist, made significant contributions to all aspects of AOG's research activities: his special interest was in fiberized laser Doppler systems. He moved to Heriot Watt University and became Professor of Engineering Optics and Head of the Department of Physics, is now Deputy Principal (Strategy and Resources) and has been awarded an OBE for scientific services to the UK.

\section{Brief background of authors of the contributed papers}

Professor Xiaoyi Bao came to the University of Kent from Germany where she was Alexander von Humboldt fellow. Her research at Kent was devoted to distributed temperature and strain measurements based on Brillouin scattering in single mode fiber using a technique called Brillouin optical time domain analysis (BOTDA). Here counter propagating laser beams at different frequencies strongly interact when their differential frequency is equal to the local value of the Brillouin frequency shift enabling the temperature/strain profile to be determined along the fiber. Together with other members of AOG she held the world record for the longest range distributed sensor. She has been a Canada Research Chair in Fiber optics and Photonics (Tier I) at the Physics Department of University of Ottawa since 2003. She is Fellow of Royal Society of Canada and fellow of OSA. In 2010 she received the Canadian Association of Physicists (CAP) and National Optics Institute (NOI)
Medal for outstanding achievement in Applied Photonics (2010). The Medal is given once every two years. In 2006 she received one of five Award Medals by Canadian National Centers of Excellence (NCE) CHAIR, and the inaugural International Creative Research Award from the University of Ottawa in 2004. She was named as the Faculty of Science Researcher of the Year Award in 2004, and the inaugural "University of Ottawa Inventor of the Year Award" in 2003, she received the Premier's Research Excellence Awards, Ontario, Canada in 2001, and the Ontario Distinguish Researcher Award in 2002, and the University of New Brunswick Merit Award in 1997.

Professor Faramarz Farahi came to the University of Kent to continue his $\mathrm{PhD}$ in theoretical Physics after completion of his MSc degree in Applied Mathematics and Theoretical Physics. In 1985 he changed his research focus and joined AOG working under supervision of Professor Jackson. His work in fiber sensors was initially focused on chemical sensing and sensor multiplexing networks. In 1990 he moved to the university of North Carolina at Charlotte, where he is currently a professor of Physics and Optics and Associate Director of the Center for Optoelectronics and Optical Communication. His research interests are: optical sensors, optical metrology and optical solar concentrators. While at Kent he and his colleagues were the first to explore the application of Brillion scattering for distributed temperature sensing, and he and his colleagues were the first to discover the phenomena of Forward Brillion Scattering in optical fibers.

Dr. Alan Kersey has been engaged in the area of fiber optic sensor research and commercialization for the past 3 decades. His research work began in 1981 at the University of Kent's Applied Optics Group, which was followed by a 14 year tenure at NRL in Washington DC from 1984 through to 1997. At NRL his focus on multiplexed sensors, led to 
some of the seminal research on multiplex Bragg grating sensor system. In 1997, Alan joined a new start-up, CiDRA corporation, as it's founding Chief Technology Officer, to develop fiber Bragg grating sensors for the Oil \& Gas industry. As CTO, he led the technical development in the company from early stage concepts to the establishment of production, market entry and business expansion. From 2003 through to 2005, he was CEO of another start-up, CyVera, which he built up from the seed stage through the establishment of manufacturing and it's acquisition by Illumina inc. His most recent role was VP \& General Manager of Illumina's UK division based in Cambridge, UK. Alan was educated in the UK, gaining a B.Sc. in Physics \& Electronics at the University of Warwick and a PhD from the University of Leeds. He has published extensively in journal and conference forums, and holds more than 100 patents in optical sensing and instrumentation.

Professor Adrian Podoleanu's research interests focus on methods and devices for optical coherence tomography (OCT). He contributed towards development of the en-face OCT imaging as a novel technology to complement the more conventional longitudinal OCT imaging and has generated simultaneously, OCT and confocal images of the retina. He is co-author of 6 chapters in books on OCT, of over 120 peer reviewed journal papers, of more than 200 conference proceedings and of 21 patents ( 9 awarded). He is one of the topical editors of the Applied Optics for the Biomedical Optics division. He was awarded a Leverhulme Trust Research Fellowship in 2004, the prize of the Ambassador of Romania to the UK in 2009 and an ERC Advanced fellowship in 2010.

António Barbosa Lobo Ribeiro graduated in Applied Physics (Optics and Electronics) by University of Porto (1990), MSc degree (1992) in Physics (Applied Optics) from University of Kent,
Canterbury, UK and the $\mathrm{PhD}$ degree (1997) in Physics from University of Porto in collaboration with University of Kent. From 1990 to 1998 he was researcher at INESC-Porto. In 2001, he co-founded the MultiWave Networks Inc., California, USA, and Multiwave Networks Portugal Lda., Maia, Portugal, being its Director of Operations until 2003. In 2006 he became consultant of Multiwave Photonics S.A, collaborating afterwards as its Product Marketing Manager until 2009. At the present, he holds the position of Associate Professor at the Faculty of Health Sciences of University of Fernando Pessoa, Porto, Portugal. Since 1990 he has been working in optical fiber sensing and more recently on fiber optic sources for biomedical applications. $\mathrm{He}$ is member of SPIE.

Professor José Luís Santos Campos Oliveira Santos graduated in Applied Physics (Optics and Electronics) by University of Porto (1983) $\mathrm{PhD}$ (1993) and Agregação (2008) from the same University. Most of the experimental research for his $\mathrm{PhD}$ was undertaken in Physics (Applied Optics) at the University of Kent, Canterbury, UK. He holds the position of Full Professor of Physics and Astronomy Department of University of Porto and is researcher of INESC Porto Optoelectronics and Electronic Systems Unit. Since 1988 he has been working in optical fiber sensing and related subjects. $\mathrm{He}$ is member of OSA, SPIE and Planetary Society.

Dr. David Webb came to Kent in 1985 to study for a $\mathrm{PhD}$ following a brief spell in industry. He left for a postdoctoral position at Oxford only to return to Kent in 1991 to spend the next ten years as an academic. His work in that period encompassed the development of novel fiber sensor interrogation and multiplexing techniques, work on distributed fiber sensors and optical coherence tomography as well as the application of fiber sensors in a wide range of fields, in particular structural monitoring, aerospace and medical sensing. At the same time he undertook 
fundamental work on photorefractive non-linear optics, on which subject he co-authored a research textbook. Since leaving Kent in 2001 he has been at Aston University where he has developed Bragg grating technology in plastic fibers as well as exploiting new technologies, e.g. fs laser material processing, for novel sensor design. Dr. Webb has published around 300 journal and conference papers, the vast majority of which are related to optical fiber sensing.

Open Access This article is distributed under the terms of the Creative Commons Attribution License which permits any use, distribution, and reproduction in any medium, provided the original author(s) and source are credited.

\section{References}

[1] D. A. Jackson, A. Dandridge, and S. K. Sheem, "Measurement of small phase-shifts using a single-mode optical fiber interferometer," Optics Letts., vol. 5, no. 4, pp. 139-141, 1980.

[2] D. A. Jackson, R. P. Priest, A. Dandridge, and A. B. Tveten, "Elimination of drift in a single-mode optical fiber interferometer using a piezo-electrically stretched coiled fiber," Applied Optics, vol. 19, no. 17, pp. 2926-2929, 1980. 